Marta Skorek

University of Gdańsk

\title{
Where Nature and Culture Meld: The Complexity of Arctic Indigenous Language Preservation from an Integrated Ecolinguistic Perspective
}

\author{
Cloudberry picking with my mom \\ is our arena of transferring \\ local knowledge and language. \\ Gunn-Britt Retter ${ }^{1}$
}

\begin{abstract}
Just as the "information age" has commenced, two of the world's great stores of information, the diversity of biological organisms and of human languages, are imperiled.

S.B. Brush ${ }^{2}$
\end{abstract}

As the importance of preserving indigenous languages has been highlighted in different fora and numerous contexts, the Arctic appears to be no exception in this regard. The vitality and sustainability of Arctic indigenous languages pervade the discourse on the polar region and lie at the core of the Arctic Indigenous Language Vitality Initiative. To explore the complexity of the endeavor, this conceptual paper analyzes the framing of Arctic indigenous language preservation in selected academic publications as well as institutional documents. Since the use of biomorphic metaphors in the context of language preservation raises numerous doubts regarding their socio-political implications, this paper attempts to address this issue from the perspective of ecolinguistics perceived as both analytical and conceptual lenses to demonstrate that its three complementary strands of research may help bridge the nature-culture divide in general and provide an integrated approach to the preservation of Arctic indigenous languages in particular.

Key words: The Arctic, indigenous peoples, language preservation, ecolinguistics, nature, culture, knowledge

\footnotetext{
1 Gunn-Britt Retter's statement as cited in: Boissoneault 2016.

2 Brush 2001: 517-530.
} 


\section{Introduction}

The Arctic has the potential to capture human imagination for a variety of reasons: its pristine environment, indigenous peoples and their cultures as well as its location on the top of the world and its vulnerability to climate change. Global environmental governance issues (e.g., global warming) epitomize complex systems that have both environmental as well as social (political, economic and cultural) dimensions. The inseparability of social and environmental systems and challenges is directly linked to the very nature of the environment as a single, complex, interconnected system that has a socio-ecological dimension (ISSC/UNESCO 2013: 4). As the circumpolar Arctic ice melts, this sensitive environment faces multiple stressors, such as radical climate change and a growing demand for the space and its resources as well as cultural, social, and economic changes affecting the livelihoods of its indigenous peoples, including the status of their indigenous languages (Grenoble and Olsen 2014: 70). To get a clear picture of the challenges at hand, the following issues need to be taken into account:

1. Arctic Indigenous languages spoken in diverse political and cultural environments in what is now Canada, Denmark, Finland, Norway, Russia, Sweden, and the United States are linked to indigenous population divisions across national borders, and assimilation policies.

2. Between forty and ninety Indigenous languages spoken in the Arctic, depending on the methods used to classify languages and dialects, and Arctic Indigenous languages belong to five main families: Inuit-Yupik-Unangax (or Eskaleut); Na'Dene (or Athabaskan); Uralic, Paleo-Asian; and Altaic.

3. Approximately four million people live in the circumpolar Arctic, of which $10 \%$ are Indigenous and the survival of their languages is threatened by competition from majority languages, urbanization, and the resulting weakening of the intergenerational transmission of Indigenous languages and limited opportunities to receive education in relevant Indigenous languages (Arctic Council Indigenous Peoples' Secretariat 2019).

In order to reverse the indigenous language shift throughout the circumpolar region, Arctic indigenous communities are cooperating within the framework of the Arctic Indigenous Language Vitality Initiative, the aim of which is to engage representatives from Arctic indigenous organizations, researchers, Arctic governments, language activists, and policy makers in the process of assessing and promoting Arctic indigenous languages (Grenoble 2013). As might be expected, the preservation of minority languages in general and Arctic indigenous languages in particular, spans a broad range of issues, including biophysical, social, cultural, political and economic ones. It is noteworthy that, while this paper focuses on the Arctic environment, the assumptions, suggestions, and conclusions formulated in the course of the research work can also hold true for other indigenous 
peoples living in places of pristine beauty (e.g., the Amazon) (cf. Stringer 2016). Therefore, the aim of this conceptual paper is three-fold:

1. To analyze the framing of Arctic indigenous language preservation in selected academic publications and in institutional documents and to present a critique of the biomorphic metaphors used in the context of indigenous language preservation.

2. To address the issue of Arctic indigenous language preservation from the perspective of ecolinguistics perceived as both an analytical and conceptual lens by demonstrating that its three complementary strands of research can help bridge the nature-culture dichotomy in general and provide an integrated approach to the preservation of Arctic indigenous languages in particular.

3. To highlight both the compatibility of the integrated ecolinguistic perspective with other scientific approaches and to point toward interesting directions for future inquiry. In other words, the overarching aim of this paper is to attempt to resolve tensions regarding the nature-culture divide in the context of Arctic indigenous language preservation and to provide multi-level insights into the complexity of this issue.

In order to fulfill these aims, the literature overview presented in this paper includes a variety of genres ranging from academic publications (books and articles) to international documents. The materials were selected by using search terms such as Arctic, Arctic environment, indigenous peoples, indigenous languages, indigenous cultures, by browsing the websites of relevant institutions and organizations, and also by establishing cross-textual links.

\section{Framing Arctic indigenous language preservation}

As might be expected, the issue of indigenous language preservation in the Arctic revolves around indigenous rights, culture, knowledge, and identity. However, the authors of the texts analyzed (academic publications and international documents) point to a clear correlation, or even a causal relationship, between language diversity and biological diversity, for example, between the extinction of species and languages. Daniel Nettle and Suzanne Romaine (2000: 13) describe the close correlation between these two categories as "a common repository... of biolinguistic diversity". It is also stressed that much of the knowledge of how to maintain biodiversity is encoded in the small languages of indigenous and local peoples, their traditional livelihoods and traditional ecological knowledge, which is place-based knowledge. In other words, the collective knowledge of biodiversity among indigenous peoples is embedded in complex local linguistic expressions and cultural practices (Wilder et al. 2016: 505; Skutnabb-Kangas 2002: 13-14) as "linguistic ecologies and biological ecologies are mutually related through human knowledge, use, and management of the environment and through the languages 
used to convey this knowledge and practices..." (Maffi 2002: 388). In the context of indigenous languages in particular it is important to note that languages constitute not only tools for communication but, first and foremost, they reflect and shape ways of thinking and doing things (Mühlhäusler 2001b: 160-161). As such, they are critical to the management of ecosystems as each language carries unique historical and ecological knowledge about the Arctic environment. What is more, they are not museum-like structures but living, evolving, dynamic systems the preservation of which helps maintain the biodiversity of the Arctic ecosystem and the well-being and traditional livelihoods of the indigenous peoples in the area (Grenoble and Olsen 2014: 69, 75). A similar intimate connection between indigenous languages and biodiversity, albeit in tropical ecoregions, is highlighted by David Stringer (2016: 17-18) who links language revitalization in indigenous cultures to the conservation of ecosystems through the encoding of ecological knowledge in the mental lexicon of a given language and the oral transmission of biocultural knowledge through stories, myths, and songs. Furthermore, both biocultural diversity and indigenous ecological knowledge are considered to be two components of human ecology in the Arctic, which is perceived as a homeland rather than a frontier for exploiting natural resources (Kassam 2009: 5, 216). Despite their being different in scope and legal force, the institutional documents analyzed converge on the issue of biocultural diversity as well. The UN Convention on Biological Diversity (United Nations 1992: 1, 6) highlights the biological and cultural dimensions of diversity, the interactions between them, and indigenous communities' dependence on biological diversity. By the same token, it makes traditional lifestyles, knowledge, and practices indispensable to the conservation of biological diversity and the sustainable use of its components. In the same vein, the Ottawa Declaration (Arctic Council 1996) establishing the Arctic Council underscores the special relationship and unique contributions to the Arctic of indigenous people and their communities as well as their involvement regarding the common issues of sustainable development and environmental protection. Adopted in 2007, the UN Declaration on the Rights of Indigenous Peoples (United Nations 2007). focuses on the right to maintain and develop their cultural heritage, traditional knowledge, and traditional cultural expressions as well as the manifestations of their sciences, technologies and cultures, including human and genetic resources, seeds, medicines, and knowledge of the properties of flora and fauna. Undoubtedly, the above-mentioned framings found in the selected academic publications and institutional documents suffice to show that indigenous language preservation is inextricably interwoven with biocultural diversity and traditional ecological knowledge, whether it be through a direct causal or a correlational link. 


\section{Critique of biomorphic metaphors}

The literature overview presented in the section above clearly demonstrates that there is a correlation between linguistic diversity and biodiversity or, to be more precise, between biodiversity and cultural diversity occurring in complex social-ecological systems, or biocultural diversity. However, the prevalence of biomorphic metaphors (e.g., ecology, diversity, survival, preservation, extinction) in the context of indigenous languages appears to raise doubts as to the implications of their use. According to Alastair Pennycook (2005), languages should not be treated as biological species (organisms interacting with their environment) but rather as shifting cultural artefacts shaped by human agency and subject to social, cultural, economic and political relations. While Pennycook (2005: 232) admits that the concept of language ecology has underscored the embeddedness of languages in their social, cultural, economic, and physical ecologies, he claims that there is no direct, causative relationship between biological and linguistic diversity as languages do not adapt to the world but represent the human endeavor to create new worlds. Undoubtedly, one should use metaphors with caution for a number of reasons. In addition to being system-bound and culture-specific concepts, metaphors have the potential of highlighting certain aspects while at the same time hiding others (Lakoff and Johnson 1980: 10-13). As Andrew Goatly (1997: 5) rightly puts it, "metaphors are not a mere reflection of a pre-existing objective reality but a construction of reality through a categorization entailing the selection of some features as critical and others as non-critical..." In the case of metaphors used in promoting socioecological sustainability "we need to go beyond the question of whether they are apt descriptors $[\ldots]$, and carefully consider their wider implications" (Larson 2011: 16-17). However, as Pennycook makes a clear division between natural systems (species, ecosystems) and cultural artefacts (people, languages), it appears to be reasonable at this point to ask the following questions: What if an attempt was made to reconceptualize the notions of ecology and diversity as well as to find a way in which the human-nature dichotomy could be bridged? Is there any research perspective that might facilitate such a change in perception? (cf. Harper 2016)

\section{Ecolinguistic perspective}

While the history of ecolinguistics can be traced back to the 1970s, which makes it a relatively young research perspective, it covers multiple approaches with different aims, goals, and methodologies with a view to examining the complex relationship between language, humans, and the physical environment. It might help us understand how our thoughts, concepts, ideas, ideologies, and worldviews shaped through language subsequently influence relations between humans and the natural 
world (Stibbe 2015). In general, the ecolinguistic research perspective has originated from erasure - the fact that the embeddedness of humans in larger life-sustaining systems has largely been overlooked in linguistics (Stibbe 2014b: 583).

\subsection{Ecolingustic research strands}

Within the analytical and conceptual framework of ecolinguistics, there are three research strands:

1. Language ecology: language diversity and all related topics, including minority languages, language endangerment and language death; the link between the loss of languages and the loss of species; further insights into language diversity and environmental diversity and the question of how language construes our view of nature and environment.

2. (Critical) ecolinguistics, also called ecological analysis of discourse, facilitating the study of the impact of language use on the life-sustaining relationship among people, other organisms, and the physical environment; analyzing clusters of linguistic and semiotic features that together produce our perception of the human-nature connection (Alexander and Stibbe 2014: 104-110); examining the role of language use in the destruction or protection of social-ecological systems; and critiquing forms of language contributing to ecological destruction and aiding in the search for new forms of language inspiring people to protect the natural world.

3. Transdisciplinary science (a dialectical philosophy) transcending traditional linguistics and creating an awareness of the interdependency of all things and ideas; a philosophy of interaction and harmony, including even more diverse philosophical traditions from all parts of the world. Within this strand, ecolinguistics is no longer seen as a discipline within the study of language but as a unified ecological worldview expressing harmony between humans and nature; the earth perceived as a living unity and a complex system (Fill and Penz 2017).

What is noteworthy is the complementarity of these ecolinguistic research strands based on the assumption that the preservation of indigenous languages contributes to the protection of life-sustaining systems as language diversity or endangerment have multiple implications for human actions or inaction and their subsequent impact on real, physical ecosystems (Alexander and Stibbe 2014: 108).

\subsection{Ecolinguistic insights into the preservation of indigenous languages}

As the complementary strands of ecolinguistics seem to be malleable enough to accommodate various research perspectives oriented toward exploring the complexities of human-nature interactions (human ecology; see Kassam 2009 for details), they are of particular relevance to the issue of indigenous language preservation 
in the Arctic. First, the ecolinguistic perspective stresses the importance of rethinking the nature-culture dichotomy as the stories about the separation between nature and culture, languages, and species no longer appear to be sustainable in light of people's embeddedness in complex natural systems (see Harper 2016; Braidotti 2019 for details), which is the case in the Arctic context. Second, it clearly demonstrates that the endangerment of the biological environment can partly be attributed to language in two ways: either through the use of particular anthropocentric language structures conditioning their speakers to rely on environmentally unsustainable perceptions (language ecology) or by particular discursive choices made by members of their language community (critical ecolinguistics) (Alexander and Stibbe 2014: 104-110). Therefore, the ecolinguistic research perspective enables one to critically analyze the use of language and its role in the destruction or preservation of life-sustaining systems, thereby resulting in increased critical language awareness (see Fairclough 2013 for details) both at the level of a given linguistic system with its lexicon and grammar (the system-critical part) and at the level of texts and their representation of a particular aspect of the world (the text-critical part) (Fill and Mühlhäusler 2001: 6). Then, it is worth noting that the perspective does not only take a negative stance toward the issue of language diversity and endangerment by questioning all those forms of language or mental models (the stories we live by) lying at the heart of the ecological challenges encountered in the Arctic, but it also aids in the search for new forms of language or stories inspiring people to protect the natural world (Stibbe 2015: 1). Finally, the transdisciplinary perspective advocated by Alwin Fill and Hermine Penz (2017) challenges the sustainable development triad of society-environment-economy as no longer adequate because it still reinforces the separation between people and nature, which runs counter to the ecological embedding of humans and human societies (Stibbe 2015: 6-7). In other words, the complementary strands of ecolinguistics also "give tired and compromised 'sustainable development' discourses a new spark of life" (Stibbe 2014a: 124). To illustrate how the above insights to be gained through the lens of ecolinguistics are relevant to the issue of indigenous language preservation in general, it is advisable to investigate the way in which the discourse on environmental governance frames human-nature interactions (human ecology). There are many terms used to capture their complexity and interrelatedness, such as society-economy-environment (sustainable development), social-ecological systems, coupled human-environment system, the human-nature connection, human ecology, humans-in-nature, economy-in-society-in-nature, biolinguistic, and biocultural diversity, which clearly demonstrates the amount of linguistic maneuvering in the English language that goes into the process of reconceptualizing the notion of ecology so that it covers a very broad concept of the "interaction of some things with other things," including the relationship of language to its biological and physical environment (Stibbe 2015: 8). Such culture-specific and context-dependent terms as the (natural) environment, the natural world, 
and the human world, reinforce the nature-culture dichotomy at the level of language use thereby shaping our perception and way of thinking (Fill and Penz 2017). This might partly be due to the fact that there is no single concept in the English language to convey the meaning of "people-in-nature" as opposed to polysynthetic, indigenous languages capturing complex natural phenomena in a single word (see Grenoble 2011: 22 for the nature of Arctic indigenous languages). Undoubtedly, the grammar and lexicon of indigenous languages reflect the fact that indigenous peoples are more attuned to their environment and have never lost their connection to the biosphere in the first place. Therefore, Peter Mühlhäusler (2001a: 37) suggests that, instead of changing their languages, speakers of Standard European Average languages become aware of the multiple ways in which other languages, including indigenous ones, emphasize and de-emphasize aspects of the environment. Furthermore, since ecolinguistics is a very rich research perspective, its object of study might also embrace the whole semiotic system, including both linguistic and non-linguistic signs (see Kress and Leeuwen 2001 for multi-modal discourse analysis applicable to all semiotic modes).

\subsection{Integrated ecolinguistic framework}

In the context of indigenous language preservation, ecolinguistics understood as an analytical and conceptual lens integrating language ecology, ecological analysis of discourse, and the transdisciplinary perspective, appears to be highly compatible with various approaches to the analysis of complex human-nature interactions. They include the following:

1. The post-normal approach to science with its emphasis on complexity and uncertainty in the context of environmental governance challenges, such as climate change or marine governance, and the pressing need to engage both experts and non-experts (extended peer community, non-academic knowledge holders) in the process of scientific knowledge production (Funtowicz and Strand 2009; Funtowicz and Ravetz 1993). This approach is largely consistent with the need to link indigenous knowledge transmitted through narratives with scientific knowledge systems (Kassam 2009: 74).

2. The concept of social-ecological systems, according to which natural and social systems should be studied as an integrated whole as people are part of nature (Folke et al. 2016).

3. The dwelling perspective in the context of human (re)connection to the biosphere (mind-body-the environment), with the (re)connection taking place not only through a mind-shift or a change of people's perception but also constituting a more embodied form of the human-biosphere connection needed to emphasize the interactions between mind, body, and the environment as people are not just mentally but also physically and materially immersed in their immediate environments (Cooke, West and Boonstra 2016: 1-13). 
It follows from the above that the nexus between the integrated ecolinguistic perspective and the above-mentioned scientific approaches facilitates the search for a non-dualistic space for reconceptualizing the nature-culture divide in general and for reconsidering numerous cross-cutting themes regarding human-nature interactions in the Arctic environment.

\section{Implications of the integrated ecolinguistic perspective for Arctic-relevant research}

Owing to the ecological turn in the humanities and social sciences, the objects of study (the mind, the human, society, culture, or religion) are no longer considered in isolation but as an inextricable and integral part of a larger physical and living world (Stibbe 2015: 7). Therefore, it can be safely assumed that such an integrated and all-encompassing ecolinguistic approach to the multi-faceted issue of indigenous language preservation can facilitate on-going research and open up new paths of scientific inquiry. This is illustrated by cases of the most important biophysical and geological places on Earth, such as UNESCO Natural World Heritage Sites, in which indigenous populations with their unique languages and cultures assume the role of stewards helping to maintain these places. By the same token, they have an opportunity to aid in the UNESCO-driven process of preserving the places where their indigenous languages and cultures have developed (Romaine and Gorenflo 2017: 1986). Moreover, indigenous and traditional knowledges can work together with diverse academic disciplines to give rise to multiple perspectives to facilitate the governance of complex social-ecological systems and the provision of ecosystem services (Ainscough, Wilson and Kenter 2018: 95). All of these interrelated issues appear to be relevant to the on-going discussion about treating the Arctic as a global common and extending the much-debated principle of the Common Heritage of Mankind to the seabed under the melting Arctic ice (see Gautam 2011; Shackelford 2009 for the development of the ideas). What is more, the integrated ecolinguistic perspective can also facilitate research projects examining the condition of indigenous languages in general, and the Arctic ones in particular, in terms of such interconnected and mutually reinforcing challenges as linguicide, ecocide (Higgins 2015), and epistemicide involving the marginalization of indigenous and traditional cultures of knowledge (de Sousa Santos as cited in: Barnett 2018: 215). 


\section{Conclusions}

It can be safely concluded that nature and culture in the Arctic are melding together, both literally and metaphorically; this phenomenon is not confined only to the polar region (see Stringer 2016 for the connection between indigenous languages and biodiversity in tropical ecoregions). Not only is the issue of indigenous language preservation framed as linguistic and cultural diversity but also as biocultural diversity contributing to ecosystem health. Such categories as nature, culture, people, species, and languages are perceived in terms of their dialectical relationship as distinct but not separate concepts. As it integrates three complementary strands of ecolingustics and accommodates multiple research perspectives, the integrated ecolinguistic perspective is particularly well-suited to investigating the multi-dimensionality of the social-ecological space in the Arctic with a strong emphasis on indigenous languages as carriers of identity, culture, and traditional ecological knowledge. The ecolinguistic perspective presented in this paper seems to correspond perfectly with the idea of consilience, according to which the unity of knowledge should be reflected across disciplines in an effort "to create a common groundwork of explanation" (Wilson 1998: 8). It is difficult to resist the impression that at the core of the problems faced by various indigenous populations, policy-makers, multi-disciplinary researchers, and other stakeholders lies our flawed human perception of the nature-culture relationship, which is in dire need of reconceptualization (see Steffensen and Fill 2014 for a unified ecological language science). While the integrated ecolinguistic perspective outlined in this paper can be seen as a drop in the ocean in the context of the multiple social-ecological challenges faced by humanity, it has the potential of becoming a pacemaker into a new scientific age characterized by transdisciplinary cooperation among nature, culture, the social sciences, and the humanities, with the central role being played by language as an integral part of all sciences (Finke 2017; Fløttum 2017; Stibbe 2014a, 2015).

\section{Bibliography}

Ainscough, J., M. Wilson and J.O. Kenter. (2018). Ecosystem services as a post-normal field of science. Ecosystem Services 31: 93-101.

Alexander, R. and A. Stibbe. (2014). From the analysis of ecological discourse to the ecological analysis of discourse. Language Sciences 41: 104-110.

Arctic Council. (1996). The Declaration on the Establishment of the Arctic Council (the Ottawa Declaration). https://oaarchive.arctic-council.org/bitstream/handle/11374/85/EDOCS-1752v2-ACMMCA00_Ottawa_1996_Founding_Declaration.PDF? sequence=5\&isAllowed=y (accessed: 6.04.2018).

Arctic Council Indigenous Peoples' Secretariat. (2019). Arctic Indigenous Peoples' languages. https://www.arcticpeoples.com/sagastallamin-arctic-languages (accessed: 18.01.2021).

Barnett, R. (2018). The Ecological University: A Feasible Utopia. New York: Routledge. 
Boissoneault, L. (2016). 318 Words for Snow: How to Preserve the Indigenous Languages of the Arctic. https://daily.jstor.org/indigenous-arctic-languages/ (accessed: 09.03.2018)

Braidotti, R. (2019). A Theoretical Framework for the Critical Posthumanities. Theory, Culture \& Society 36(6): 3-161.

Brush, S.B. (2001). Protectors, Prospectors, and Pirates of Biological Resources. In: L. Maffi (ed.). On Biocultural Diversity. Linking Language, Knowledge and the Environment. WashingtonLondon: Smithsonian Institution Press, pp. 517-530.

Cooke, B., S. West and W.J. Boonstra. (2016). Dwelling in the biosphere: exploring an embodied human-environment connection in resilience thinking. Sustainability Science 11(3): 1-13.

Fairclough, N. (ed.). (2013 [1992]). Critical Language Awareness. London: Routledge.

Fill, A. and H. Penz. (2017). Ecolinguistics in the 21st Century. New Orientations and Future Directions. In: A.F. Fill and H. Penz (eds.). The Routledge Handbook of Ecolinguistics. New York: Routledge.

Fill, A. and P. Mühlhäusler. (2001). Introduction. In: A. Fill and P. Mühlhäusler (eds.). Ecolinguistics Reader: Language, Ecology and Environment. London: Continuum.

Finke, P. (2017). Transdisciplinary Linguistics. Ecolinguistics as a Pacemaker into a New Scientific Age. In: A.F. Fill and H. Penz (eds.). The Routledge Handbook of Ecolinguistics. New York: Routledge.

Fløttum, K. (2017). Language and Climate Change. In: K. Fløttum (ed.). The Role of Language in the Climate Change Debate. New York: Routledge.

Folke, C., R. Biggs, A.V. Norström, B. Reyers and J. Rockström. (2016). Social-ecological resilience and biosphere-based sustainability science. Ecology and Society 21(3): 41.

Funtowicz, S. and J.R. Ravetz. (1993). Science for the post-normal age. Sciernce Direct, http:// www.sciencedirect.com/science/article/pii/001632879390022L (accessed: 6.06.2015).

Funtowicz, S. and R. Strand. (2009). Models of Science and Policy. In: T. Traavik and L.C. Lim (eds.). Biosafety First: Holistic Approaches to Risk and Uncertainty in Genetic Engineering and Genetically Modified Organisms. Trondheim: Tapir Academic Press.

Gautam, P.K. (2011). The Arctic as a Global Common. IDSA Issue Brief, https://www.files.ethz. ch/isn/135416/IB_TheArcticasaGlobalCommon.pdf (accessed: 5.05.2018).

Goatly, A. (1997). The Language of Metaphors. London: Routledge.

Grenoble, L.A. (2011). On thin ice: language, culture and environment in the Arctic. In: J. Sallabank (ed.). Language Documentation and Description. Vol 9. London: SOAS, pp. 14-34.

Grenoble, L.A. (2013). The Arctic Indigenous Language Initiative: Assessment, promotion, and collaboration. In: M.J. Norris, E. Anonby, M.O. Junker, N. Ostler and D. Patrick (eds.). Endangered Languages Beyond Boundaries. Langues en péril au-delà des frontières. Proceedings of the 17th FEL Conference, Ottawa, Canada, 1-4 October 2013. Bath: Foundation for Endangered Languages FEL.

Grenoble, L.A. and C.C. Olsen. (2014). Language and well-being in the Arctic: Building indigenous language vitality and sustainability. Arctic Yearbook 2014, https://www.arcticyearbook.com/ images/Arcticles_2014/Grenoble_AY2014_FINAL.pdf (accessed: 16.03.2018).

Harper, F.Z. (2016). Talking about Nature: Ecolinguistics and the Natureculture Paradigm. In: A.C. Dinerstein (ed.). Social Sciences for an Other Politics. Women Theorizing without Parachutes. Cham: Palgrave Macmillan, pp. 93-105.

Higgins, P. (2015). Eradicating Ecocide: Laws and Governance to Stop the Destruction of the Planet. London: Shepheard-Walwyn (Publishers) Ltd.

ISSC/UNESCO (2013). World Social Science Report 2013: Changing Global Environments. Paris: OECD Publishing and UNESCO Publishing. http://www.worldsocialscience.org/documents/ wss-report-2013-summary-en.pdf (accessed: 10.07.2014). 
Kassam, K.A.S. (2009). Biocultural Diversity and Indigenous Ways of Knowing: Human Ecology in the Arctic. Calgary: University of Calgary Press.

Kress, G. and T. van Leeuwen. (2001). Multimodal discourse: The modes and media of contemporary communication. London: Arnold.

Lakoff, G. and M. Johnson. (1980). Metaphors we live by. Chicago: University of Chicago Press.

Larson, B. (2011). Metaphors for Environmental Sustainability: Redefining Our Relationship with Nature. New Haven, CT: Yale University Press.

Maffi, L. (2002). Endangered Languages, Endangered Knowledge. International Social Science Journal 173(3): 385-393.

Mühlhäusler, P. (2001a). Talking about Enviromental Issues. In: A. Fill and P. Mühlhäusler (eds.). Ecolinguistics Reader: Language, Ecology and Environment. London: Continuum.

Mühlhäusler, P. (2001b). Babel Revisited. In: A. Fill and P. Mühlhäusler (eds.). Ecolinguistics Reader: Language, Ecology and Environment. London: Continuum.

Nettle, D. and S. Romaine. (2000). Vanishing Voices: The Extinction of the World's Languages. Oxford: Oxford University Press.

Pennycook, A. (2005). Language policy and the ecological turn: language ecology - a way of understanding language and environment. Language Policy 3(3): 213-239.

Romaine, S. and L.J. Gorenflo. (2017). Linguistic diversity of natural UNESCO world heritage sites: bridging the gap between nature and culture. Biodivers Conserv 26: 1973-1988.

Shackelford, S.J. (2009). The Tragedy of the Common Heritage of Mankind (May 19, 2009). Stanford Environmental Law Journal 27. Stanford Public Law Working Paper No. 1407332. SSRN: https://ssrn.com/abstract=1407332.

Skutnabb-Kangas, T. (2002). Why should linguistic diversity be maintained and supported in Europe? Some arguments. Guide for the Development of Language Education Policies in Europe. From Linguistic Diversity to Plurilingual Education. Strasbourg: Council of Europe.

Steffensen, S.V. and A. Fill. (2014). Ecolinguistics: The state of the art and future horizons. Language Sciences 41A: 6-25.

Stibbe, A. (2014a). An Ecolinguistic Approach to Critical Discourse Studies. Critical Discourse Studies 11(1): 117-128.

Stibbe, A. (2014b). Ecolinguistics and Erasure: restoring the natural world to consciousness. In: C. Hart and P. Cap (eds.). Contemporary critical discourse studies. London: Bloomsbury Academic.

Stibbe, A. (2015). Ecolinguistics. Language, Ecology and the Stories We Live By. New York: Routledge.

Stringer, D. (2016). When grasshopper means lightning: How ecological knowledge is encoded in endangered languages. Langscape 5(1): 14-19.

United Nations. (1992). The UN Convention on Biological Diversity. https://www.cbd.int/doc/ legal/cbd-en.pdf (accessed: 1.02.2016).

United Nations. (2007). The UN Declaration on the Rights of Indigenous Peoples. https://www. un.org/development/desa/indigenouspeoples/wp-content/uploads/sites/19/2018/11/ UNDRIP_E_web.pdf (accessed: 2.03.2017).

Wilder, B.T., C.O'Meara, L. Monti and G.P. Nabhan. (2016). The Importance of Indigenous Knowledge in Curbing the Loss of Language and Biodiversity. BioScience 66(6): 499-509.

Wilson, E.O. (1998). Consilience. The Unity of Knowledge. New York: Vintage Books. 